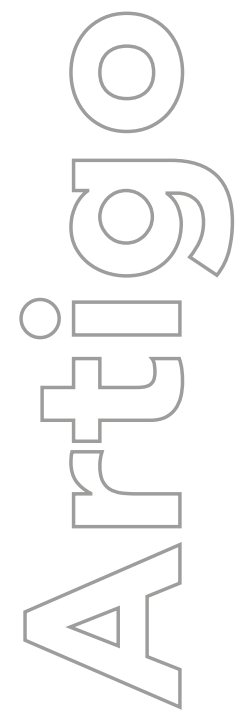

revista

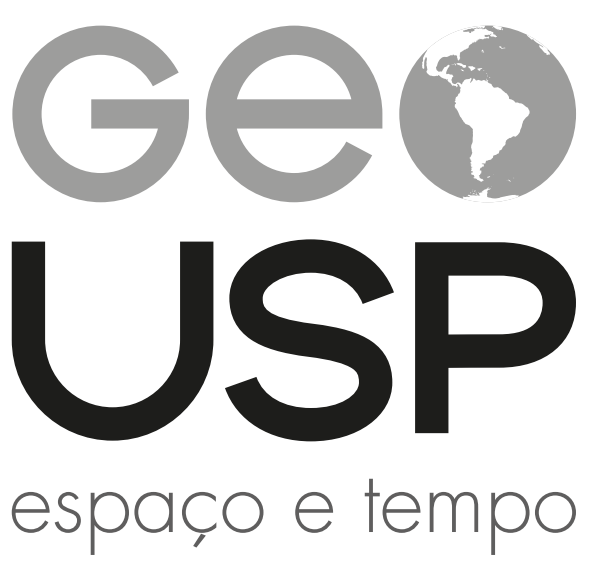

Volume $25 \cdot n^{\circ} 2$ (2021)

ISSN 2179-0892

\section{Território usado e cultura urbana: o circuito hip hop na metrópole de Havana (1979-2015)}

Cristiano Nunes Alves

Universidade Estadual do Maranhão. São Luís.

Maranhão. Brasil cris7cris7@yahoo.com.br

(1) 0000-0002-2843-9491

e-181649

Como citar este artigo:

ALVES, C. N. Território usado e cultura urbana: o circuito hip hop na metrópole de Havana (1979-2015). Geousp, v. 25, n. 2, e-181649, 2021, ISSN 2179-0892.

Disponivel em: https://www.revistas.usp.br/geousp/article/ view/181640. doi: https://doi.org/10.11606/issn.2179-0892. geousp.2021.181649

\section{(c)}

Este artigo está licenciado sob a Creative Commons Attribution 4.0 Licence 


\title{
Território usado e cultura urbana: o circuito hip hop na metrópole de Havana (1979-2015)
}

\section{Resumo}

Refletindo sobre o território usado, operacionalizamos a noção de circuito cultural, destacando materialidades e ações dinamizadas pela cultura hip hop na metrópole de Havana, capital de Cuba. Baseados em levantamento bibliográfico e documental, além do trabalho de campo, propomos uma periodização (1979-2003) para o hip hop havaneiro, e, em seguida, apresentamos uma análise da contemporaneidade do circuito (2015), abordando: (i) seus discursos e (ii) a tipologia-topologia de seus fixos, fluxos e agentes. Observa-se um circuito periférico dinamizado sobretudo por ações de resistência, fortemente caracterizadas pelo improviso, impondo o protagonismo dos sujeitos que, fundindo estética e política, conferem amarração à metrópole a partir dos lugares.

Palavras-chave: Território usado. Circuito cultural. Resistência. Hip hop. Cuba.

\section{Used territory and urban culture: the hip hop circuit in the metropolis of Havana (1979-2015)}

\begin{abstract}
Reflecting on the used territory, we operationalized the notion of cultural circuit, highlighting the materialities and actions promoted by hip hop culture in the metropolis of Havana, capital of Cuba. Based on a bibliographic and documentary survey, in addition to fieldwork, we propose a periodization (1979-2003) for Havana hip hop, and then we present an analysis of the circuit's contemporaneity (2015), highlighting: (i) their speeches; and (ii) the typology-topology of its fixed assets, flows and agents. It is possible to observe a peripheral circuit dynamized specially by actions of resistance, in a large part characterized by improvisation, imposing the protagonism on the subjects who, merging aesthetics and politics, give articulation to the metropolis from the places.
\end{abstract}

Keywords: Used territory. Cultural circuit. Resistance. Hip hop Cuba. 


\section{Territorio usado y cultura urbana: el circuito hip hop en la metrópoli de La Habana (1979-2015)}

\section{Resumen}

Reflexionando sobre el territorio usado, operacionalizamos la noción de circuito cultural, destacando las materialidades y acciones impulsadas por la cultura hip hop en la metrópoli de La Habana, capital de Cuba. A partir de un relevamiento bibliográfico y documental, además del trabajo de campo, proponemos una periodización (1979-2003) del hip hop habanero, y luego presentamos un análisis de la contemporaneidad del circuito (2015), analizando: (i) sus discursos; y (ii) la tipología-topología de sus activos fijos, flujos y agentes. Es posible observar un circuito periférico dinamizado especialmente por acciones de resistencia, poderosamente caracterizadas por la improvisación, imponiendo el protagonismo a los sujetos que, fusionando estética y política, dan amarre a la metrópoli desde los lugares.

Palabras-clave: Territorio usado. Circuito cultural. Resistencia. Hip hop. Cuba.

\section{Introdução}

Surgido na Nova York de fins dos anos 1960 e hoje uma cultura mundializada (Calogirou, 1996; Toop, 2000; Alves, 2015; Hammou, 2008), o hip hop chegou à ilha de Cuba no final dos anos 1970. Tem-se, desde então, na chamada cultura das ruas, um considerável dado da realidade urbana dessa nação que, em represália a seu governo resultante de uma revolução socialista, encontra-se desde 1960 sob um embargo econômico (El Bloqueo) liderado pelo governo dos EUA.

Em seu contexto de surgimento num bairro predominantemente negro de Nova York South Bronx - o hip hop significou o protesto sistemático contra a desigualdade e a segregação socioterritoriais sofridas pela população negra e latina, majoritariamente de ascendência antilhana. Os hip hoppers, sujeitos dinamizadores da cultura das ruas, organizam-se por meio de ações de resistência compostas por três expressões artísticas: o rap (manifestação musical), o break (manifestação corpórea) e o grafite (manifestação visual). ${ }^{1}$

Por sua vez, o hip hop cubano, amálgama de narrativas, ritmos e estilos afro-cubanos e caribenhos - caso, entre outros, do repente cubano — dinamiza-se denunciando a um só tempo as contradições do capitalismo e do socialismo, como propõe Kirkwood (2006, p. 3):

1 A música rap compõe-se, em geral, a partir de narrativas do cotidiano urbano, cantadas por MC (mestres de cerimônia) e tocadas por DJ (disk jockeys). Já o break consiste numa dança misturada com golpes de artes marciais e organizada por meio de batalhas. Finalmente, o grafite é um estilo de pintura em lugares como muros, viadutos e vagões de trem, entre outros. 
Impactado pelo pensamento marxista, pela herança africana, pelo discurso antihegemônico e pelos triunfos e armadilhas da própria Revolução, o movimento hip-hop cubano é um fenômeno verdadeiramente único, cujos efeitos ainda não foram compreendidos.

Período de consolidação da cultura das ruas em Cuba coincide com a entrada no chamado período especial, momento de ampla crise vivida no país, iniciado nos anos 1990, em virtude da queda do regime socialista soviético e que implicou duras medidas de austeridade por parte do governo cubano. Esse período tem sido marcado pelo incremento das desigualdades sociais e raciais (Fernandes, 2003). Não por acaso, o hip hop se movimenta basicamente por meio da ação de jovens negros e mestiços, pertencentes aos estratos sociais menos favorecidos, logo, oriundos de lugares associados à pobreza (Selier Crespo, 2005).

Neste artigo, objetivamos analisar geograficamente o hip hop na metrópole de Havana amparados na noção de território usado (Santos, 1997), uma construção histórica e política instrumental para compreender a situação concreta - condição e resultado da dinâmica de ações e materialidades - constituinte do espaço geográfico² e dos seus lugares em Cuba. Tomado como sinônimo de espaço geográfico, todavia, fazendo avultar "a necessidade de um esforço destinado a analisar sistematicamente a constituição do território" (Santos; Silveira, 2001, p. 20) o território usado é definido por Silveira (2011, p. 35) como um "quadro de vida" capaz de abrigar os mais diversos agentes e desígnios. Tem-se, outrossim, uma entrada para investigar a dialética entre o território imposto como recurso por poderes hegemônicos e o território vivido como abrigo (Gottmann, 2012[1975]) por sujeitos hegemonizados, caso daqueles que dinamizam a cultura hip hop.

Ora, em suas condições espaciais e históricas específicas, o território usado parece se constituir como importante fundamento de método para a leitura geográfica da contemporaneidade, fornecendo subsídios para uma análise acerca dos sujeitos, dos lugares e de suas solidariedades (Ribeiro, 2010).

Complementando nossa proposta, operacionalizamos a noção de circuito cultural (Alves, 2013), ferramenta teórico-metodológica que aponta a dinâmica de materialidades e relações sociais em torno de determinada manifestação cultural. Interessa-nos, assim, o circuito da cultura das ruas, constituído por meio: (i) dos fixos, dos objetos e dos sistemas técnicos; e (ii) dos fluxos, das articulações e das informações.

Intentamos, nesse viés, refletir sobre as ações de resistência do circuito, essas que, irrompendo a partir dos lugares e dos sujeitos, indicam uma postura crítica frente a todo tipo de desigualdades socioterritoriais. Tal abordagem convida-nos a pensar na noção de ação como elemento rítmico do território usado, fator decisivo na produção da metrópole por meio da cultura e da arte.

2 Para Santos (1997, p. 232), "A utilização do território pelo povo cria o espaço", produção unificada de duas demandas: a tecnoesfera, a dimensão da materialidade, do mundo físico e dos objetos, em geral associada a demandas externas aos lugares; e a psicoesfera, a dimensão imaterial, dos fluxos informacionais, das ideias, das crenças, das paixões e das ideologias, lugar da criação de valores e hábitos. Nessa perspectiva, segundo Smith (1988, p. 123), a produção do espaço resulta da associação entre a vida material e a consciência: "a produção do espaço [...] implica a produção do significado, dos conceitos e da consciência do espaço que estão inseparavelmente ligados a sua produção física”. 
Nossa metodologia de trabalho consistiu num levantamento bibliográfico ${ }^{3}$ e temático sobre a questão em arquivos impressos e digitais, minúcia compreendendo: (i) teses, (ii) dissertações, (iii) livros, (iv) artigos em periódicos, (v) artigos em jornais, (vi) cartazes de eventos artísticos e outros materiais visuais, (vii) fonogramas e (viii) conteúdo de blogs e sites da internet.

Também compuseram o desenvolvimento de nossa pesquisa trabalhos de campo realizados em Cuba entre os meses de março e abril de 2015. Em municipalidades das províncias de Artemisa e de Havana, capital do país, ${ }^{4}$ visitamos fixos ligados ao circuito hip hop tais como locais de eventos artísticos, estúdios fonográficos e a Agencia Cubana de Rap. Ainda nesse escopo, em entrevistas semiestruturadas, dialogamos com cerca de 30 sujeitos envolvidos no tema, entre os quais, raperos, DJ, breakers, produtores musicais e visuais, articuladores culturais, agentes do governo ligados ao hip hop e aficionados em geral. As interlocuções oriundas de nossos trabalhos de campo estão no texto acompanhadas de asterisco ${ }^{*}$, significando informação primária.

Organizamos este texto do seguinte modo: num primeiro momento, investigamos a história territorial do circuito hip hop em Havana e, numa perspectiva cara ao exame das formações socioespaciais (Santos, 1977), propomos uma periodização (Santos, 1997) para a cultura das ruas, compreendendo o ínterim 1979-2003. Depois, apresentamos um panorama do circuito hip hop cubano de 2015, pondo em relevo seus discursos de resistência e a tipologia e a topologia de seus fixos, fluxos e articulações abrigados na metrópole de Havana.

Ao olhar para a dinâmica do circuito hip hop cubano, queremos contribuir para a reflexão geográfica discutindo o modo como, por meio da cultura urbana, se dinamizam ações de resistência articulando as esferas política e estética do território usado.

\section{Investigando a história territorial da cultura hip hop em Cuba: uma proposta de periodização para o circuito (1979-2003)}

Buscando o enfoque genético do circuito hip hop, temos, conforme Isnard (1978), que, se a sociedade e o espaço evoluem de modo paralelo, correspondendo cada geração humana a uma geração espacial, urge olhar o tempo de modo apurado, sendo ele um potencial revelador das diversas organizações espaciais. Assim, indagando os processos formadores dos lugares a partir da cultura urbana, apresentamos uma periodização do hip hop na ilha.

\section{Prelúdio: em Cuba, circulação das primeiras informações sobre a cultura hip hop (1979-1985)}

Ainda que desde 1960 o território cubano sofra severas restrições econômicas, políticas e sociais em razão do embargo, uma série de informações a respeito da cultura hip hop foram paulatinamente chegando à ilha.

Assim, estimulando-nos a abordar o fluxo de informações por meio do circuito, Exner (2004) lembra que, em 1979, a música "Rapper's Delight" do grupo The Sugarhill Gang, se torna o primeiro

3 As citações de bibliografia estrangeira estão no texto em tradução livre do autor.

4 A cidade de Havana, capital de Cuba, é ainda o núcleo da província homônima composta por 15 municipalidades, aglomeração urbana que abriga ao todo 2.201 .610 pessoas (2018), cerca de $22 \%$ da população cubana, estimada em aproximadamente 11.450 .000 habitantes. Procurando ultrapassar análises economicistas dos lugares, defendemos o estatuto metropolitano de Havana, considerando sua dimensão política, cultural e informacional. 
sucesso do rap estadunidense, tendo a informação chegado a Cuba por sinais de rádio e TV captados no entorno da base militar estadunidense de Guantánamo, extremo leste cubano. A autora lembra ainda que, no mesmo ano, os cerca de 100.000 cubanos emigrados, principalmente para Miami, por conta da Revolução, passam a ter o direito de trânsito para Cuba, levando consigo uma série de objetos técnicos e práticas caras às modernizações do mundo capitalista.

Igualmente nessa via, aportaram em Cuba novos elementos, como as vestimentas ou os equipamentos eletrônicos, além de referências musicais distintas, circulantes por meio de fitas, discos ou mesmo antenas piratas de rádio ou TV, logo implicando o espraiamento da audição, entre os cubanos, de gêneros como o rhythm E blues ( $r$ Eb b e o próprio rap.

Por sua vez, Perry (2016), rememora, no ano de 1983, a difusão na televisão local do videoclipe da música Rock it do pianista estadunidense Herbie Hancock, faixa na qual uma série de elementos estéticos do hip hop são apresentados, tal qual a técnica do scratch ${ }^{5}$ ou os movimentos do break. Igualmente a esse termo, no ano de 1986, difunde-se na TV estatal cubana o videoclipe da música Sun City, integrante de um projeto artístico contra o apartheid na África do Sul, intitulado Artistas Unidos, com a presença de importantes figuras da velha escola do hip hop estadunidense como Kool Herc, Afrika Bambaataa e Run DMC (Garcia, 2014, p. 522). Têm-se aí os primeiros fluxos informacionais da chegada da mensagem hip hop à ilha.

\section{Período formador da cultura das ruas em Havana: ações de resistência e dinâmicas nos lugares (1986-1991)}

O caráter precursor havaneiro abrigando o hip hop cubano faz-nos lembrar que as metrópoles, lócus da mescla cultural, abrigos de uma complexa teia de relações e de intensos fluxos materiais e imateriais (Santos, 1994), apresentam-se como os lugares onde, ao longo do tempo, por meio também da produção artística em geral, melhor se conjugam inovações técnicas, estéticas e políticas.

Vejamos: assim como observado em outros países, caso do Brasil ou da França, o break, chamado de rompehuesos, praticado pelos bailadores, foi a expressão inicial do hip hop a se manifestar em Cuba. Exner (2004), inclusive, propõe que no final dos anos 1980, em Havana, já havia se formado em torno da cultura das ruas - mais especificamente em torno do break - um pequeno grupo de sujeitos, conhecidos como moñeros, assim chamados em virtude da adoção de gorros (moñas) e bandanas como elementos de distinção.

Naquele momento, restringindo-se à audição musical, sem adentrar a produção, esses jovens se encontravam em desafios de break (as chamadas batalhas) realizados em locais públicos como o Parque Maceo (Malecón), a Casa De La Cultura Del Municipio (Diez de Octubre), e, mais tarde, a praça La Piragua (Malecón) (Exner, 2004).

Com o tempo, a partir de bases musicais estadunidenses sem letras, surgem os primeiros raps cubanos, processo no qual fora decisiva a ação dos raperos de Alamar, bairro periférico de população predominantemente negra, na zona leste da Região havaneira.

Fazendo-nos refletir sobre o papel aglutinador dos lugares, impulsionando os circuitos culturais, uma série de estudiosos (Olavarria, 2002; Garcia, 2014; Perry, 2016) sugere que Alamar despontou como região pioneira do rap cubano, pois era único lugar da ilha onde - devido a sua posição de

5 O scratch consiste na produção de sons percussivos ou rítmicos pelo arranhamento de discos de vinil com as mãos dos DJ. 
sítio, relativamente mais próxima do estado da Flórida, nos EUA-, se podiam sintonizar regularmente sinais de rádios estadunidenses difusoras do rap, influência para o circuito que se delineava. Tratava-se de um grande conjunto habitacional no modelo soviético, abrigo de cerca de 300 mil pessoas, outrora modelo de projeto social, mas que, com a entrada no período especial, tornar-se-ia um lugar repleto de problemas, como a carência de transporte público para o resto de Havana (Olavarria, 2002). Sobre a origem do hip hop cubano, Cosme Oliva, um dos pioneiros do movimento, afirma (*): "Como Alamar era um lugar muito urbano, onde as pessoas estavam muito concentradas, criou-se um núcleo da cultura hip hop. Então se organizaram os primeiros festivais e a cultura se espalhou".

Nesse contexto, impuseram-se ações de resistência frente à precariedade do lugar, tais como a construção de antenas improvisadas pelos jovens residentes de Alamar, no intuito de captar os sinais de emissoras de Miami especializadas em rEb e rap, caso da WHQT Hot 105 FM, da 1040 AM e, sobretudo, da 99 Jams FM, tida como grande influência do desenvolvimento inicial do hip hop cubano.

A esse termo, parcela considerável de nossos interlocutores afiança ${ }^{(*)}$ que o impulso para a identificação com o hip hop foi o discurso trazido por essa cultura, contrário à discriminação e à segregação do povo negro.

Logo a difusão de informações no circuito se aprofunda, e o hip hop se espraia pela província de Havana e por outros pontos de Cuba, manifestando-se na metrópole havaneira em lugares como o bairro de Lawton, por meio do break, dinamizado pelos breakers, chamados de bonches de calle (bonecos de rua) nos retos (desafios) de dança, e dos cantos raperos coletivos realizados no Parque de Los Policias, contexto no qual a falta de bases musicais gravadas fazia com que se improvisasse a levada do rap a partir de batidas em cajas (caixas) de percussão (Perry, 2016, p. 66).

Logo, a imitação do rap estadunidense daria lugar a um movimento de ressignificação, pela incorporação de elementos musicais cubanos ao rap criado na ilha (Olavarria, 2002; Fernandes, 2003) - dinâmica alicerçada, do ponto de vista dos objetos e sistemas técnicos, na circulação de fitas cassete contendo bases musicais oriundas do estrangeiro ou gravações das programações de emissoras estadunidenses captadas em Alamar.

Em nossa análise espaço-temporal do circuito, acordamos com Fernandes (2003), que, buscando sintetizar as variáveis em torno do hip hop cubano até então, propõe que um período formador ter-se-ia encerrado em 1991, grosso modo após um quinquênio, caracterizado pela difusão da cultura das ruas em contextos socioterritoriais específicos, ligados às escalas comunitárias.

Iniciar-se-ia, assim, um novo período do hip hop em Cuba, marcado pela institucionalização e pela comercialização dessa cultura, desenvolvida por meio de um estilo original, envolvendo ao mesmo tempo "instituições estatais cubanas, gravadoras transnacionais e organizações do hip hop estadunidense" (Fernandes, 2003, p. 578). Em nosso exame, cindimos esse período em dois subperíodos, abordando-os a seguir.

\section{Aprofundamento do circuito hip hop havaneiro: ações de resistência e articulação entre os lugares (1991-1997)}

No início de um novo momento, observa-se o espraiamento do hip hop por diversas áreas da província de Havana e do entorno que têm em comum uma considerável densidade 
demográfica e o fato de abrigarem essencialmente sujeitos pobres e/ou negros, caso de Havana Velha, Centro Havana, Santos Suarez e Playa (Fernandes, 2003). Consolidam-se, assim, os grupos pioneiros do rap cubano, caso, entre outros, do Anónimo Consejo (Habana del Este), do Obsesión (Regla), do Doble Filo (Centro), do Amenaza (Cayo Hueso) e do Primera Base (Guanabacoa). ${ }^{6}$

Nesse contexto, em 1991, organizaram-se apresentações de hip hop - as peñas - em lugares como as Casas de la Cultura de Mónaco e Diez de Octubre, no mesmo momento em que, na rádio Metropolitana de Havana, cria-se o programa La Esquina de Rap (Fernández Díaz, 2002). No ano seguinte, a Asociación Hermanos Saiz (AHS), promotora de artistas cubanos com menos de 35 anos e extensão da Unión de Jóvenes Cubanos (UJC), passa a organizar na Praça La Piragua (Malecón) uma série de apresentações de hip hop ao ar livre (Kirkwood, 2006; Perry, 2016).

No ano de 1994, toda essa movimentação se desloca para o Clube Local (rua Carlos III), um espaço criado por DJ Adalberto e marcado pela emergência dos pioneiros do rap cubano, então praticantes do improviso musical característico desse gênero, o chamado freestyling (Fernandes, 2003).

Odensamento das espessuras cooperativas em torno do hip hop em Cuba implicou, em junho de 1995, a organização em Alamar, ainda de modo "subterrâneo" (Fernández Díaz, 2001, p. 6), o Primeiro Festival Cubano de Rap, evento artístico de imensa repercussão espacial, representando a consolidação do Movimento de rap cubano (Selier Crespo, 2005). Esse Festival resultou da articulação entre a AHS e o Grupo Uno, coletivo artístico sediado na Bahia, zona leste havaneira e liderado pelos produtores Balesy Rivero e Rodolfo Rensoli.

Meditando acerca das primeiras redes e ações articulando a chegada em Cuba de informações sobre o hip hop, cumpre pontuar que o pai de Rodolfo Rensoli fora um dos marinheiros responsáveis por levar à ilha uma considerável discografia estrangeira, incluindo produção fonográfica ligada ao rap (Garcia, 2014). Salutar mencionar ainda, o fato do Coletivo Uno ter sido responsável pela organização, meses antes do Festival, de eventos artísticos como o Rap Plaza 96 (Casa de La cultura Plaza, Centro) e as batalhas de rap no Vedado e na Bahia, estas congregando raperos de bairros de Havana Leste como Alamar, Cojimar, Regla e Guanabacoa (Perry, 2016). Com o Festival de 1995, sobressai a preponderância da questão negra no hip hop produzido na ilha: venceu o concurso de melhor canção "Igual que tú", do grupo Primera Base, referência ao ativista do movimento negro estadunidense Malcom X.

Nesse sentido, Perry (2016) propõe que o ano de 1997 sinalizaria uma maior abordagem de aspectos sociais e raciais no Festival, tendo sido ganhadora do evento a música "Ochavón cruzado" (Oitavão mestiço), do grupo Amenaza — que se tornaria o grupo Orishas —, "um rap que contestava a ideia de harmonia racial em Cuba" (Garcia, 2014, p. 524).

Ainda sobre as ações de resistência negra articulando os lugares a partir do circuito hip hop, Fernandes (2003) e Perry (2016) sublinham as conexões entre o ativismo negro e

6 Entre os pioneiros do rap cubano, cumpre ainda destacar grupos como Bajo Mundo, Barbarito, El Pelón, Explosión Suprema, EPG, Rapeiros Crazy de Alamar e Wilder 01. 
a cultura das ruas em Cuba, manifestas, entre outros fatores, na influência de Nehanda Abiodun e de Asata Shakur, ativistas estadunidenses exiladas na ilha, pois ligadas a movimentos negros revolucionários, e na articulação com grupos como o Black August Planning Organization, movimento criado nos anos 1970 por presos políticos do sistema prisional californiano, buscando congregar as diferentes resistências negras das Américas.

Assim, a partir de 1996, o Black August agiu visando apoiar o Festival, então abrigado no Anfiteatro de Alamar, definindo entre seus objetivos o auxílio "por meio de doações, delegações e fomentando o intercâmbio de artistas vinculados ao rap de consciência (política) nos Estados Unidos com seus colegas cubanos" (Selier Crespo, 2005, p. 2).

Igualmente resultado da articulação com essa organização negra, a partir da edição de 1997 do Festival, iniciou-se a presença de rappers estadunidenses como Moss Deff, Comon, Deff Press, Talib Kwali e The Roots, bem como de rappers da América do Sul e da Europa (Selier Crespo, 2005). Estavam, desse modo, lançados os fundamentos do subperíodo posterior, de consolidação do hip hop cubano.

\section{Consolidação do hip hop cubano: institucionalização e difusão fonográfica alhures (1998-2003)}

Período de consolidação do circuito hip hop cubano é marcado tanto por contradições inerentes ao processo de institucionalização quanto por sua relação com a produção fonográfica.

Nesse contexto, apesar das limitações de ordem técnica, o Festival tomou grandes proporções ganhando em "qualidade, assistência e poder de convocação" (Exner, 2004, p. 72), chegando a reunir cinco mil pessoas. Frente à magnitude do Festival em 2001, o governo cubano proibiu sua realização em Alamar, fato que, por um lado, indicou a burocratização estatal, e, por outro, implicou que, em 2003, o evento fosse em Havana Centro, durando sete dias, contando com 20 grupos estrangeiros, aglutinando 68 agências de imprensa e, assim, atraindo correspondentes do mundo todo (Exner, 2004; Selier Crespo, 2005).

A institucionalização do hip hop cubano não se restringiu à tutela do Festival: em setembro de 2002, fundou-se a Agencia Estatal Cubana de Rap, objetivando "movimentar a política do gênero, apoiá-la, evitar sua marginalização e dar-lhe reconhecimento público" (Vázquez, 2002, p. $6^{7}$ apud Exner, 2004, p. 73). Destarte, no mesmo ano, passaria a circular a revista cubana de hip hop Movimiento, coordenada pela AHS, bem como, criam-se cursos oficiais de aperfeiçoamento para os raperos, tratando de temas como a história afroamericana (Exner, 2004).

Como implicação do adensamento do circuito hip hop cubano, observam-se também o aumento do intercâmbio entre grupos locais e estrangeiros e a difusão alhures da produção fonográfica do rap cubano.

Nessa perspectiva, no ano de 1999, o grupo cubano Orishas (Cayo Hueso, Havana), radicado na França, assinava um contrato com a gravadora EMI, e lançava o seu disco de estreia intitulado "A Lo Cubano", produção com massiva repercussão mundial. Exner (2004, p. 73) sugere ter se tratado do ensejo para que a imprensa estrangeira classificasse o rap

7 VÁZQUEZ, O. Nueva proyección para el rap cubano. Granma, 2002. 
cubano "como um suposto receptáculo de dissidência e subversão, atribuindo-lhe uma posição antagônica ao sistema político de Cuba". Nesse contexto, o então Ministro da Cultura, Abel Prieto, reúne-se com a militância hip hop, declarando o rap uma "autêntica expressão cultural cubana", criando-se ainda espaços no rádio e na TV para a difusão do gênero (Ávila González, 2000, p. $25^{8}$ apud Exner, 2004).

Enquanto isso, em Cuba, a produção do rap se desenvolve satisfatoriamente, ainda que em meio à precariedade técnica, logrando obter originalidade e inovação, arejando o gênero. Essencial nesse processo, tem-se a ação do produtor musical Pablo Herrera, responsável por um estúdio caseiro no bairro havaneiro de Santos Suarez, cujo "rudimentar equipamento de produção, incluía máquina de batidas digitais, teclado eletrônico e monitores doados por contatos de Nova York" (Perry, 2016, p. 37).

Por sua vez, resultado da articulação com o Black August, no ano de 2001, ocorreria a turnê estadunidense dos grupos Obsesión e Anónimo Consejo, acompanhados pelo promotor de rap da $\mathrm{AHS}$, Ariel Fernández e por Pablo Herrera.

$\bigcirc$ referido intercâmbio concorreu para o lançamento do álbum coletânea Cuban HipHop All Stars v. 1, produzido por Pablo Herrera e lançado pelo selo (pequena gravadora) novaiorquino Papaya Records, contando com a presença de grupos como Anónimo Consejo, 100\% Original, Obsesión, Grandes Ligas, Las Krudas, Explosión Suprema e Los Paisanos (Perry, 2016). No mesmo ano de 2001, em Cuba, ocorre o lançamento de outra compilação, intitulada Con Los Puños Arriba, produzida pela Empresa Estatal de Grabaciones y Ediciones Musicales (Egrem) e lançada ainda no Canadá (Exner, 2004).

Assim, no início dos anos 2000, observa-se que, além de manifestações residuais em parques ou praças, conforme atesta nosso campo de informação primária(*), os grupos de rap passam a ter aceitação em locais de grande prestígio cultural, caso dos teatros Mella e América, enquanto bairros como Vedado, Cerro e Centro Havana consolidam-se como lugares de encontro da militância hip hop.

\section{O que revela a periodização do hip hop cubano: topologia e tipologia do circuito}

Rematando a topologia do circuito hip hop havaneiro analisada no período entre 19792002 (Figura 1), observam-se: (i) a predominância de quatro áreas de maior concentração de variáveis: Alamar, Vieja/Centro Havana, Santos Suarez e Vedado, (ii) a ação de oito grupos de rap pioneiros, três deles com base em Vieja/Centro Havana, (iii) cinco locais preferenciais para a prática do break, dois deles próximos ao Malecón, e (iv) a operação de oito estúdios fonográficos ligados ao rap, sete deles no eixo entre as municipalidades da Plaza de la Revolución, Cerro e Vieja/Centro Havana.

8 ÁVILA GONZÁLEZ, M. Apreciaciones en torno al movimiento de rap cubano. Extramuros, n. 2, p. 22-26, 2000. 
Figura 1 - Topologia do hip hop havaneiro (1979-2003)

\section{O circuito hip hop na Regiāo de Havana $(1979-2003)$}
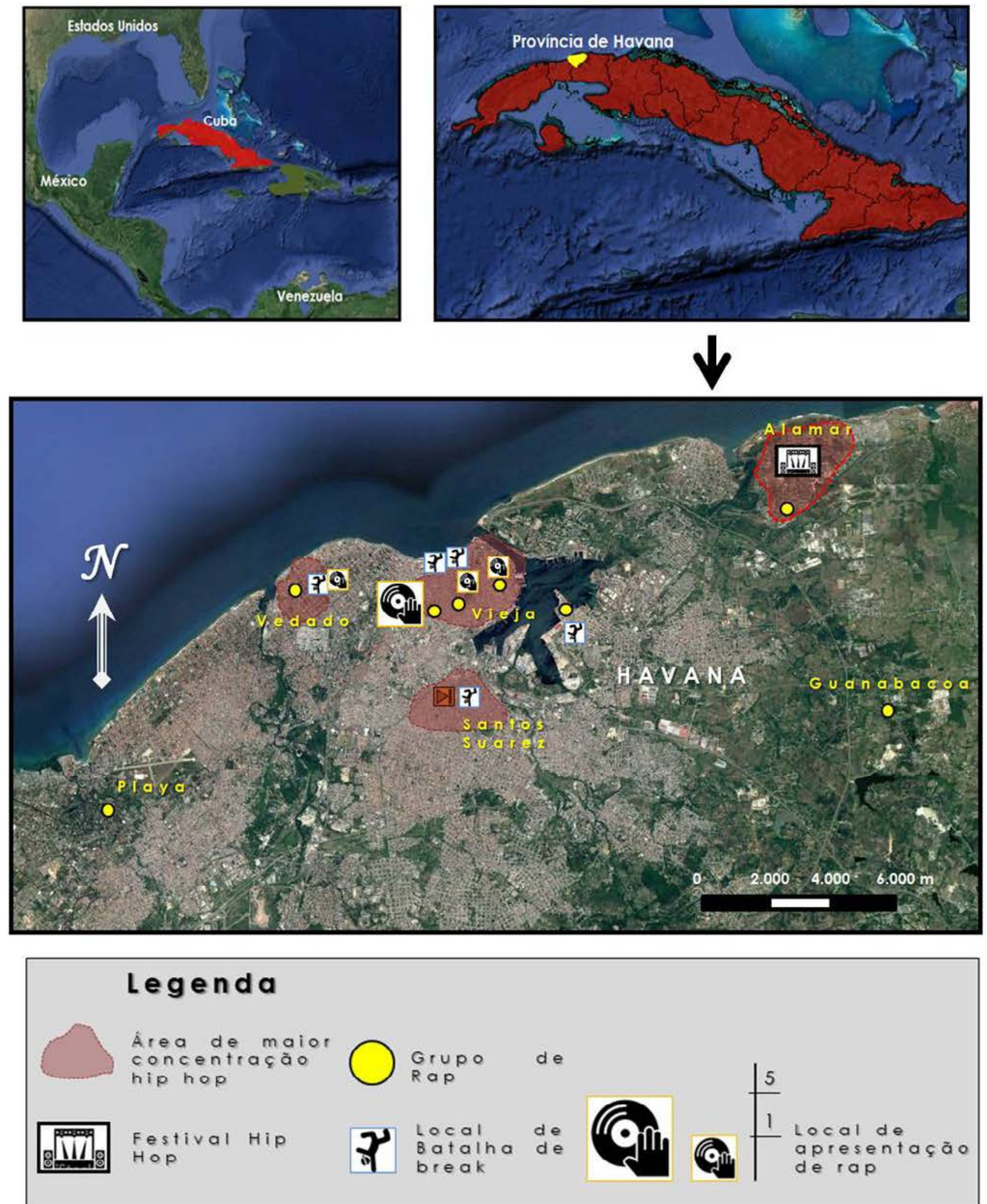

Elaboraçāo cartográfica: autoria propria, 2017.

Base: Google Earth 
Em contrapartida, nossa periodização do circuito hip hop aponta um prelúdio (entre 1979 e 1985), quando o conhecimento sobre a cultura das ruas aporta em Cuba por meio de fluxos informacionais difundidos pela emissora de televisão estatal e por cubanos emigrados retornando (em definitivo ou não) ao país. À vista disso, lançam-se as bases para a gradual conformação em Cuba de uma psicoesfera (Santos, 1997) favorável à comunicação de ideias sobre o hip hop, impulsionando ações de resistência contra a desigualdade e o racismo e em favor da arte.

No período posterior, de formação do circuito (de 1986 a 1991), dinamizam-se em determinadas periferias de Havana, primeiramente em torno do break e, em seguida, em torno do rap, variáveis indicando, por meio do hip hop: (i) a predominância do uso de espaços públicos, (ii) um alto grau de improviso embutido em ações e objetos e (iii) o diálogo com gêneros e estilos artísticos cubanos.

Subsequentemente, num período de aprofundamento (1991-1997), o circuito hip hop passa não só a dinamizar variáveis em determinadas periferias havaneiras, como também extrapola a vida de relações desses lugares: delineia-se, então, uma rede metropolitana articulando lugares em torno da cultura das ruas. Nesse contexto, Alamar, periferia leste da metrópole, desponta como lugar pioneiro, destacando-se ainda a afirmação dos grupos de rap, o papel difusor do Festival Cubano de Rap e redes de cooperação articulando o circuito e organizações do movimento negro estadunidense.

Por fim, no período de consolidação do circuito (1998-2003), caracterizado pela sua conflituosa relação com o Estado e com o mercado fonográfico, observam-se, entre outros, a formação, em Havana, de um calendário de eventos em torno do rap e a difusão de alguns grupos de rap cubanos fora do país.

Uma vez realizado esse esforço visando sintetizar os pormenores da dinâmica tempoespacial do circuito, tecemos uma análise do eixo das recentes coexistências espaciais ligadas ao tema.

\section{Espessuras recentes do circuito hip hop cubano (2015): sujeitos, discursos, lugares e técnicas}

Entre os impasses do hip hop cubano, nossos interlocutores atestam que El Bloqueo segue sendo um dos principais problemas para a sociedade como um todo, fato que, destarte, repercute também na cultura das ruas, como explica o promotor cultural pioneiro Cosme Oliva ${ }^{(*)}$ :

Para o rapero, o rap é parte de sua vida. Não pode viver sem o rap [...] A dificuldade é o grande bloqueio que Cuba tem sofrido. Porque há muitas gerações, temos bons músicos, bons raperos, mas o que ocorre é que temos que lutar pelo acesso aos beats (batidas musicais), isso custa muito trabalho, ter acesso à técnica, à internet, isso dificulta. A internet é fundamental.

O contexto cubano, em meio ao período especial, sinaliza hoje para uma remuneração mensal média de 118 pesos (cerca de seis dólares) e a circulação de duas moedas: o peso cubano, como entrevisto, de pouco valor no contexto internacional, utilizado para transações internas, e o peso convertível (CUC), equivalente ao dólar estadunidense e utilizado, mormente, em transações turísticas e de comércio exterior. Nesse contexto, cumpre importante papel o envio 
de remessas dos emigrados para a ilha, bem como as divisas oriundas do turismo, privilegiando quem dispõe de dólares (Ebanks, 1998).

A realidade cubana leva Zurbano (2009) a afirmar que a discussão sobre a existência de uma postura comercial e uma postura independente não tem sentido num país onde não existe um mercado fonográfico, ao passo que, para Fernández Díaz (2002), os próprios raperos se dividem entre essas posturas. Assim, os independentes seriam definidos pela forte ligação com a evolução do rap, respeitando suas premissas estéticas, e por um engajamento político por meio de letras e da ação social. Por seu turno, os raperos comerciais caracterizar-se-iam, especialmente, pela incorporação "dos ritmos cubanos populares para serem mais aceitos" (Fernández Díaz, 2002, p. 43), tornando os raps comercializáveis.

Desse modo, no contexto cubano, sugere Fernandes (2003), enquanto os raperos comerciais atraem uma maior audiência, fazendo concertos para cerca de cinco mil pessoas, sendo ouvidos ainda em residências, festas ou em sons de carros pelas ruas, os mais independentes fazem shows em locais de pequeno porte, para plateias menores.

Fernandes (2003, p. 589) afirma ainda que, para além do espraiamento de uma consciência política em busca da justiça social, parcela dos raperos age de outro modo, baseando-se em estratégias de sobrevivência constitutivas do chamado jineterismo, conjunto de atividades na fronteira da legalidade ligadas ao turismo.9 Ajuda-nos a entender tal estratégia cara ao período especial se levarmos em conta que, em contraste com a remuneração entre US\$ 7 e US\$15 mensais obtida trabalhando em tempo integral para o governo, um jinetero ganha entre US\$40 e US\$ 80 por dia (Fernandes, 2003, p. 590).

A seguir, procuramos esmiuçar melhor o atual panorama em torno do circuito hip hop cubano, tratando dos discursos de resistência embutidos nessa manifestação cultural.

\section{O discurso de resistência do hip hop cubano: negritude, feminismo e revolução}

Ainda que caracterizado pela falta de unidade em seu discurso de resistência, o hip hop cubano tem traços que indicam uma veemente crítica ao modo de vida no período especial, assinalando intrincados e contraditórios aspectos da sociedade e do território cubanos. Nesse sentido, por meio da produção fonográfica do rap, por exemplo, emergem temas como a dinâmica das ruas, a pobreza, o bloqueio contra Cuba, o colonialismo, o racismo, o machismo, a homofobia, o turismo sexual e as contradições do regime socialista.

Segundo Zurbano (2012), o rap cubano é um poderoso meio de expressão do povo negro, resultado da grande diáspora africana, substância para a criação de uma consciência emancipada e transnacional. Já para Garzón (2014), na medida em que substancia a discussão sobre o racismo e a negritude, tem-se no rap cubano uma experiência de liberdade.

Nesse viés, deve-se lembrar que a sociedade e o território cubanos são fortemente influenciados pela cultura africana, levada à ilha pelos povos negros escravizados no período colonial. Kirkwood (2006) pontua que, ao contrário do ocorrido nos EUA, em Cuba, como

9 Entre essas atividades, podemos destacar serviços de táxi e transporte em geral, serviços de guias informais e comércio de rum ou de charutos. 
forma de manter a produtividade escravista, os negros tiveram permissão para manter sua língua, suas práticas religiosas e demais tradições. Tal fato levou a que, ainda hoje, persista uma série de características ligadas à cultura africana, permeando os mais diversos aspectos das práticas espaciais.

Substanciando o discurso do hip hop contra o racismo, ocorre a crítica ao governo cubano "por ignorar questões de raça na sociedade cubana declarando a erradicação do racismo" (Fernandes, 2003, p. 584). Dá ideia do racismo presente na sociedade cubana o relato de Rodriguez (2010, p. 17) ponderando que o cabelo no estilo black não é tão aceitável em certos setores da sociedade cubana, ao mesmo tempo em que, numa tentativa de desvalorizar a luta do povo negro, afirma-se não existir discriminação racial no país:

Não era concebível que os negros tivessem algo para protestar contra, em um país onde a Revolução tinha estabelecido a igualdade de direitos e oportunidades para brancos e negros. Supunha-se que o racismo era um flagelo inerente ao sistema capitalista e que o socialismo o havia extirpado completamente da nossa sociedade. A administração da escola não podia ver o afro como um simples penteado.

Selier Crespo (2005) propõe que, assim como a influência de organizações esquerdistas estadunidenses, a marginalidade (racial e de classe) seria um dos elementos chave para que se possa entender a sobrevivência do movimento hip hop cubano.

Ainda por meio do Movimento de Rap Cubano, posicionam-se as mulheres, parte delas alinhada ao novo feminismo caribenho, conforme demonstra o trabalho de uma série de grupos femininos e de raperas como Magia Lopez, Lucy, Las Krudas (Pasita e Olivia), Las Positivas, Danay e Afibola.

A esse termo, as raperas Reina Y Rainha ${ }^{(*)}$ falam da luta pela paulatina inserção da mulher no rap cubano, ao passo que Selier Crespo (2005) lembra que segundo as atas da Divisão de Música da AHS, a presença feminina no hip hop em Cuba é de cerca de 10\%, fato que endossa o lema de que "não há revolução sem as mulheres".

Isso posto, sublinhamos que a constituição do rap cubano como plataforma de um discurso de resistência implica a pujança do conceito de iHip Hop, Revolución!, criado em 1998 pelo grupo Anónimo Consejo, asseverando a necessidade de "pegar as coisas como elas são e revolucioná-las", criando novos modos de pensar, escrever e viver (Sekuo, $2003^{10}$ apud Selier Crespo, 2005, p. 11).

Todavia, a crítica da militância hip hop às mazelas sociopolíticas cubanas não se faz sem que haja censura ou sem que se criem polêmicas com o governo, como entrevisto no caso de Papá Humbertico ao cantar seu tema La Habana que no conoces, uma denúncia contra a repressão policial que, com a ascensão do turismo, ganha terreno, atingindo sobretudo a população jovem e negra, justamente aquela que dinamiza a cultura das ruas (Exner, 2004; Selier Crespo, 2005).

10 Líder do grupo cubano de rap Anónimo Consejo. 
Na visão de Exner (2004), o governo cubano, dirigente da Agencia Cubana de Rap (Fotos 1, 2 e 3) - que tem 23 grupos de rap associados e emprega 30 funcionários -, teria uma estratégia consciente de certa dubiedade com relação ao hip hop: até certo ponto, apoia as necessidades artísticas dos jovens, conferindo à cultura das ruas um status de arte nacional elaborada, ao mesmo tempo em que engendra uma dependência dos artistas da (conflituosa) institucionalidade estatal, o que inclui a busca pelo alinhamento temático aos ideais da Revolução Cubana.

\section{Fotos 1, 2 e 3 - A Agencia Cubana de Rap}
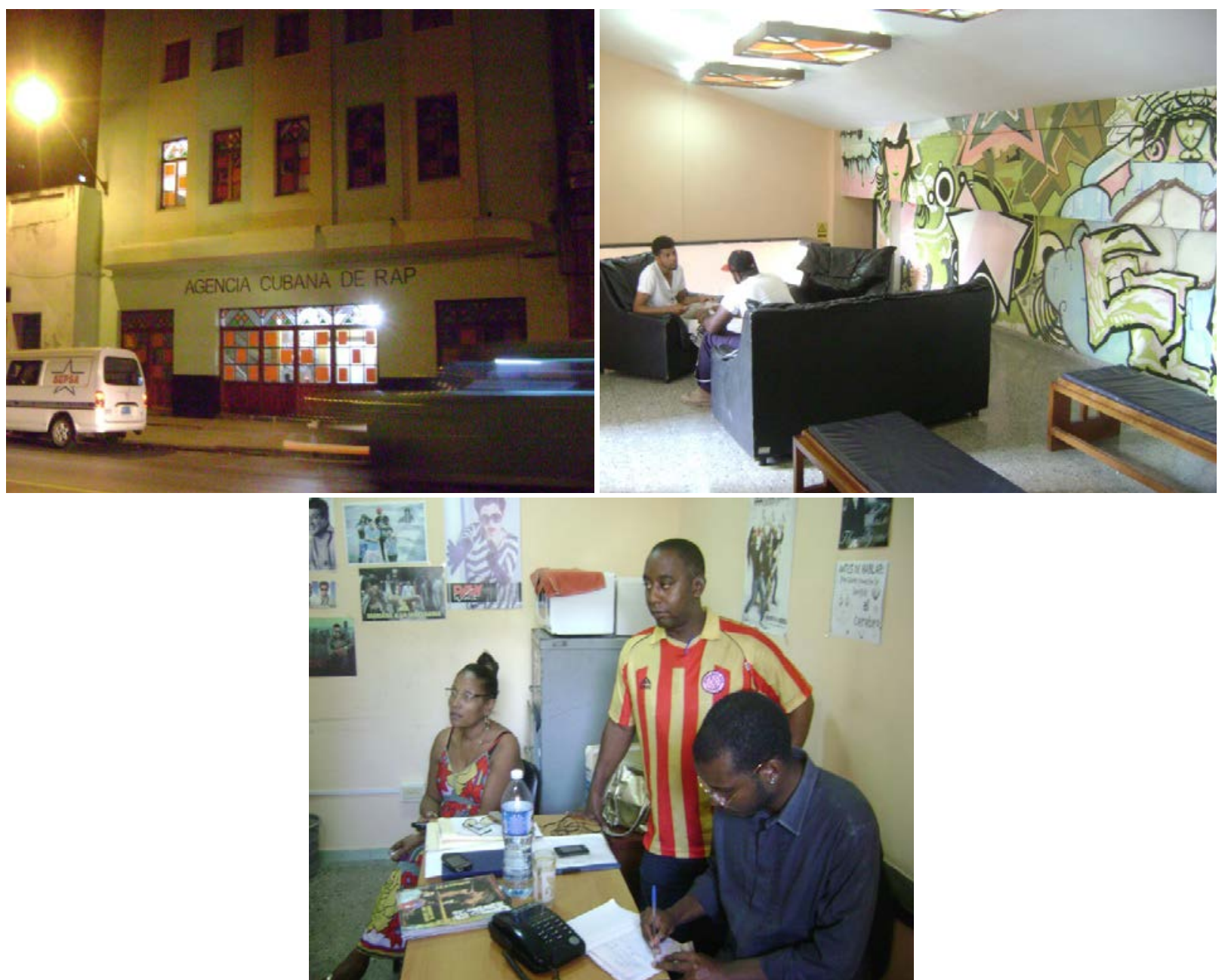

fonte: Acervo pessoal do autor, 2015.

Por fim, ressaltando a articulação do rap cubano alhures (Fotos 4, 5, e 6), acompanhamos in loco a gravação do fonograma (Artemisa) e do videoclipe (Havana) da música "Uma só voz" dos grupos Inquérito (Nova Odessa, Brasil) e La Invaxión (Artemisa). 

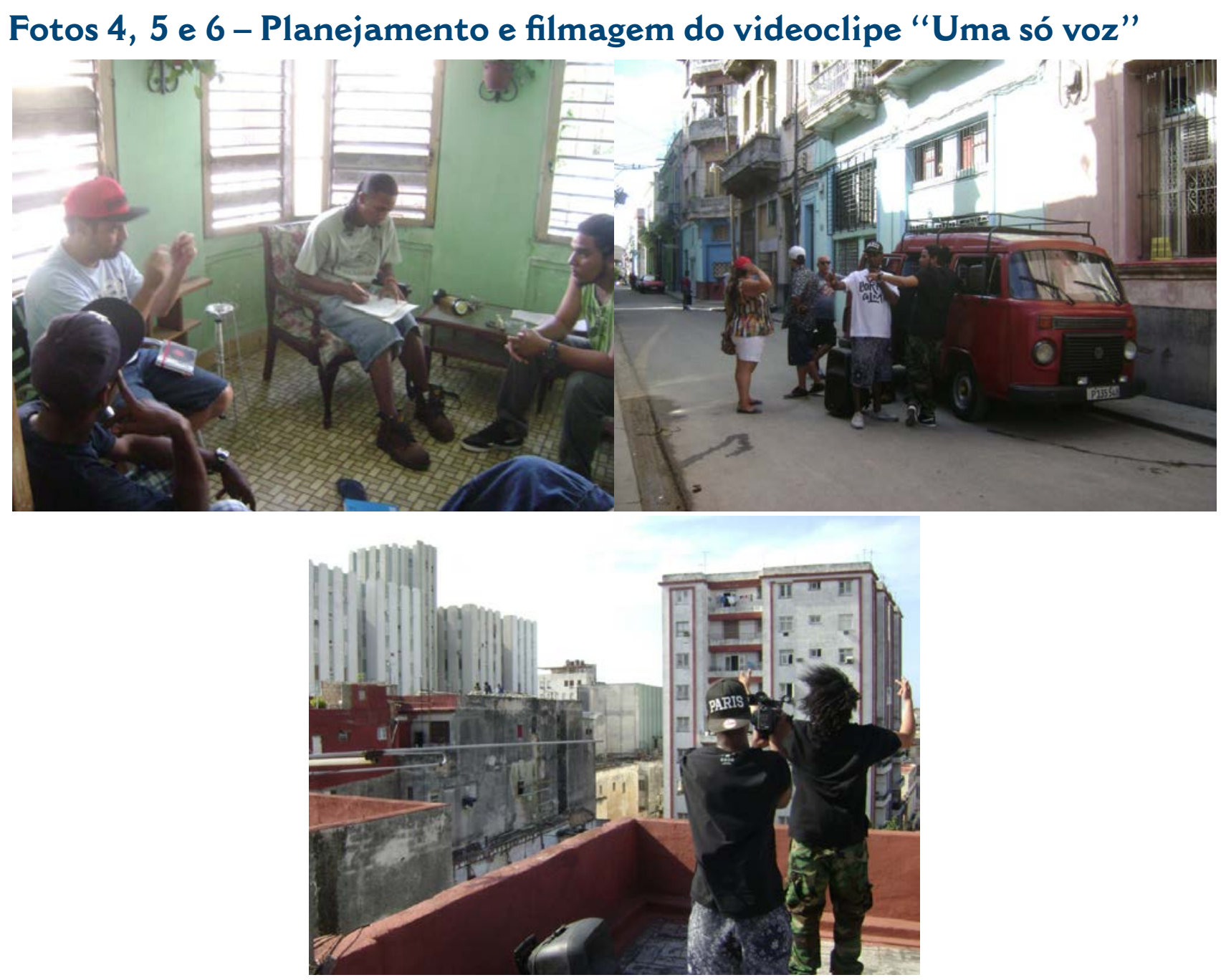

fonte: Acervo pessoal do autor, 2015.

A ideia do projeto decorreu de um contato do rapista brasileiro Renan Inquérito, líder do renomado grupo Inquérito, com o rapero cubano luri — radicado em Montevidéu (Uruguai), e um dos fundadores do Grupo La Invaxión, composto ainda por Black Soul e Yusniel Cepero. Observa-se, assim, por meio do circuito hip hop cubano, uma tessitura latino-americana fundada em ações de resistência.

\section{Inventariando o circuito hip hop em Havana: fixos, fluxos e articulações}

Conforme exposto, desde o final dos anos 1970 o circuito hip hop se espraia a partir dos subúrbios da metrópole de Havana. Amparados em informações de campo, atestamos que hoje, além dos 17 grupos associados à Agencia Cubana de Rap, agem outros 24 grupos abrigados na Região de Havana e no seu entorno. Seis desses grupos estão radicados fora de Cuba, perfazendo 47 grupos inventariados.

Sobre a espessura dos grupos de rap em Cuba, Cosme Oliva assevera(*): "Existem muitos grupos, nas ruas há muitíssimos grupos. Não há controle de quantos grupos existem em Havana ou nas províncias". A topologia dos grupos de rap indica maiores concentrações nos bairros populares de Diez de Octubre, Alamar, Vedado e Playa, seguidos de Guanabacoa e Habana Vieja (Figura 2). 
Inventariou-se, ainda, a existência de 13 estúdios fonográficos mais ligados ao rap na região, ao passo que não se observou a existência de selos hip hop, para além das iniciativas estatais. A topologia dos estúdios fonográficos mostra que as maiores concentrações ocorrem em Habana Vieja, Alamar e Diez de Octubre. Apurou-se que o custo de instalação de um estúdio mais ligado ao rap varia em torno de US\$600,00 a US\$700,00 - empenho, em geral, realizado ao longo de vários anos, de acordo com a possibilidade financeira de seus produtores.

Afirma-se entre os produtores do rap, a positiva relação custo-benefício advinda desses fixos: "são muito mais baratos e não há tanta diferença de qualidade", esclarece o produtor Moisés Mo(*), proprietário de um estúdio situado em San Miguel Del Padrón (sudeste havaneiro). Constatou-se que, em Cuba, a produção de um disco de rap custa em média cerca de US $\$ 200,00$ a US $\$ 300,00$ US\$, dos quais US\$100,00 a US\$200,00 correspondem às despesas de estúdio (gravação e masterização, entre outros). Mostrando a multiplicidade de tarefas que um sujeito do circuito pode assumir, em geral, os próprios grupos distribuem e comercializam o fonograma, como esclarece o rapero Yusniel Cepero(*).

\section{Figura 2 - Topologia contemporânea do rap havaneiro}
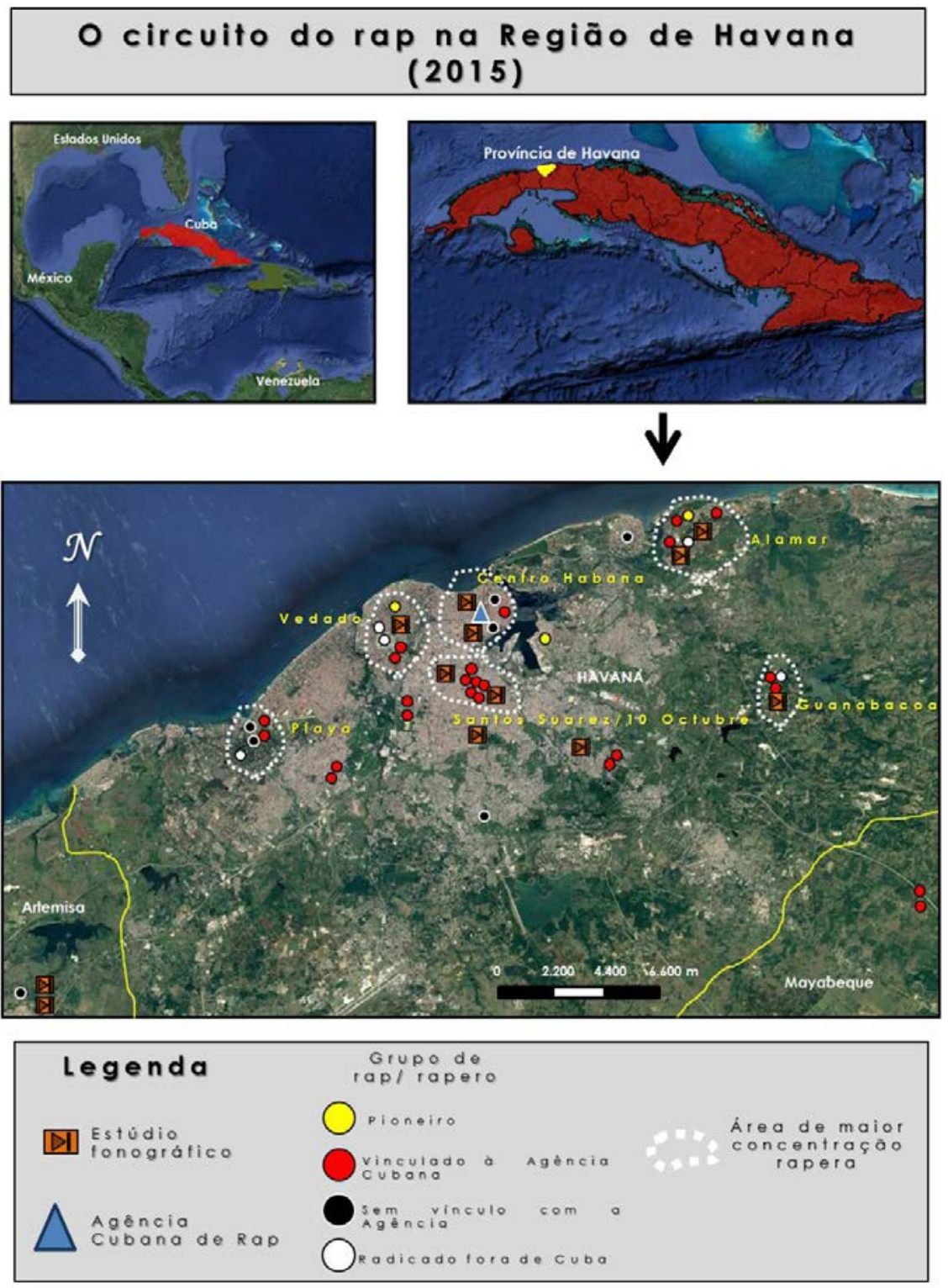

Elaboraçao cartográfica: autoria própria. 2017.

1010: 600010 toen 
A exemplo do observado no Brasil (Alves, 2013, 2015), a maior parcela dos estúdios fonográficos ligados ao rap funciona em fixos improvisados nas próprias residências dos produtores, situação na qual a precariedade da produção parece não afetar a riqueza da música produzida.

Cumpre ressaltar, por outro lado, a parca presença do grafite em Cuba, consequência da falta de certos materiais causada pelo bloqueio, como tintas de qualidade: as poucas mensagens nesse sentido são feitas com estêncil, moldes, látex e a tinta que houver disponível.

Associados às dinâmicas tanto do rap quanto do grafite no circuito hip hop cubano - engendradas por sujeitos e envolvendo lugares, objetos e fixos em situações de desigualdade socioterritorial - essas implicam a noção de "flexibilidade tropical" (Santos, 1994), caminho possível para refletir sobre a modernização incompleta das cidades do Terceiro Mundo." Aparentemente, tal "arte de resolver a vida" (Ribeiro, 2004), experienciada em particular pelos sujeitos pobres que movimentam o circuito, é a força motriz das ações de resistência do hip hop cubano.

No que tange à articulação do circuito hip hop no país, ${ }^{12}$ pulula no território cubano uma série de eventos artísticos, congregando a militância nacional e estrangeira. ${ }^{13}$ Retrato dessa situação, Cuba conta com um calendário de eventos (artísticos e/ou científicos) regulares ligados ao hip hop, caso do Simpósio de Hip Hop e do Festival Puños Arriba (Havana), ou do Nacidos en el Asfalto, evento de break realizado em Bayamo.

Além dos eventos regulares, abriga-se em Cuba - sobretudo em Havana - uma série de outros eventos ligados ao hip hop, como as apresentações abrigadas na Fabrica de Arte Cubana (Revolución), Callejón de Hame (Maceo), ou no Cine-teatro Acapulco (Alturas), caso do show de comemoração dos sete anos do grupo Los Aldeanos, realizado no ano de 2010, reunindo mais de duas mil pessoas por meio de uma divulgação baseada no boca a boca.

\section{Conclusão}

A investigação do hip hop em Havana a partir da noção de circuito revela uma produção cultural urbana nos lugares e envolta em relações de conflito com o Estado ou com a indústria cultural. Assim, observa-se um circuito cuja dinâmica se sustenta no conhecimento da vivência cotidiana nos lugares: um saber se comportar e se comunicar, condição para a manutenção da autonomia.

Pleno de particularidades, pois acompanhando traços da formação socioespacial que o abriga, o hip hop cubano se dinamiza desde o final dos anos 1970 numa nação onde as modernizações se dão de um modo generalizadamente incompleto.

Caracterizado decisivamente pela luta do povo negro, com crescente participação de mulheres e apesar da dificuldade de acesso às possibilidades técnico-informacionais do período

11 Segundo Santos (1994), pautados na lida cotidiana em meio à precariedade, os espaços opacos das urbes abrigariam modos de fazer alternativos a uma racionalidade hegemônica, tornando possível a sobrevivência.

12 Ainda parte de nosso inventário, destacamos o papel de Santiago de Cuba como um lugar importante para o hip hop cubano. Observam-se na cidade ações de militantes como Borrash El Independiente ou Isnay Rodríguez, núcleos de ação hip hop como o Laboratório G1-2K (Grupo de Apoyo Kultural a la Komunidad) e grupos femininos como o Las Positivas, formado pelas raperas La Directa e La Justa.

13 São exemplos dessa movimentação, entre outros, La Jornada de Hip Hop Rapdicando, ocorrida em Holguín, em 2013 , reunindo grupos como La Malcom Baby (La Habana), El Sketch (Santiago de Cuba), Cuerda Floja (Holguín), Baconao y Marumba (Camagüey), Conciencia (La Habana), El Tanque (Villa Clara), La invasión (La Habana), Dj Alex 6 (Holguín), Son de madre (Holguín), Ar Chain (Angola) e Proyecto Electrozona (Holguín). 
atual, hoje o hip hop cubano mobiliza uma série de variáveis espaciais, mostrando-se um dado relevante da cultura urbana nacional.

Segundo o nosso inventário, Havana abriga atualmente inúmeras variáveis ligadas ao hip hop, tais como grupos de rap, estúdios e produtores fonográficos e a Agencia Cubana de Rap. De outra parte, as manifestações da cultura das ruas substanciam um calendário anual de eventos artísticos (concertos, festivais e oficinas) em diversos pontos do país.

A experiência havaneira revela um circuito dinamizado mais por ações — de resistência, muito caracterizadas pelo improviso - do que por objetos, impondo o protagonismo dos sujeitos que, fundindo estética e política, conferem amarração à metrópole a partir dos lugares: eis as caraterísticas de um território não apenas usado, mas também "praticado" (Ribeiro, 2003), um território em uso, sendo usado.

Trata-se, sem dúvida, de uma perspectiva que merece maior aprofundamento, intentando, pois, a aproximação entre a análise geográfica e a vida dos sujeitos nos lugares.

\section{Referências}

ALVES, C. N. Quando as ruas abrigam a arte: a cena hip hop no Recife (1980-2014). Confins - Revue Franco-brésilienne de Géographie, v. 25, p. 1-18, 2015. doi: https://doi.org/10.4000/confins. 10426.

ALVES, C. N. O circuito hip hop na região de Campinas. Mercator, v. 12, n. 28, p. 125-140, 2013. Disponível em: http://www.mercator.ufc.br/mercator/article/view/659. Acesso em: 13 maio 2021.

CALOGIROU, C. Le Florida, lieu musical entre banlieue et centre-ville: l'exemple des rappeurs agenais. Les Annales de La Recherche Urbaine, n. 70, p. 48-57, 1996. Disponível em: https://www.persee.fr/doc/aru_0180-930x_1996_num_70_1_1927. Acesso em: 13 maio 2021.

EBANKS, G. E. Urbanization in Cuba. PSC Discussion Papers Series, v. 12, n. 10, 1998.

EXNER, I. Poderes y paradojas en una (sub-)cultura emergente: observaciones acerca del movimiento de hip hop en La Habana. Iberoamericana, v. 4, n. 14, p. 69-89, 2004.

FERNANDES, S. Fear of a Black Nation: local rappers, transnational crossings, and state power in contemporary Cuba. Anthropological Quarterly, v. 76, n. 4, p. 575-608, 2003.

FERNÁNDEZ DÍAZ, A. ¿Timba con Rap? El hip hop de la polémica. Salsa Cubana, v. 5, n. 17, p. 43-45, 2002.

FERNÁNDEZ DÍAZ, A. Rap cubano: poesía urbana o la nueva trova de los noventa. E1 Caimán Barbudo, v. 33, n. 296, p. 4-14, 2001.

GARCIA, A. F. Cultura política no rap cubano. In: SIMPÓSIO NACIONAL DE HISTÓRIA, 29., 2017, Brasilia. Anais... Brasilia, 2017.

GARCIA, A. F. A marginalização ocupa a rua: o rap em Cuba. Revista Brasileira do Caribe, São Luis-MA, Brasil, v. XIV, n. 28, p. 503-536, jan./jun. 2014. 
GARZÓN, Y. P. Identidades juveniles y consumo musical de "reggae" y "rap" en Cuba. Desidades, v. 2, n. 5, p. 9-16, 2014.

GOTTMANN, J. A evolução do conceito de território. Boletim Campineiro de Geografia, Campinas, v. 2, n. 3, p. 523-544, 2012[1975].

GUILLARD, S. "Représenter sa ville": l'ancrage des identités urbaines dans le rap des Twin Cities. Cybergeo - Revue Européenne de Géographie, 2012. doi: https://doi.org/10.4000/ cybergeo. 25357.

HAMMOU, K. L'économie du rap français. In: FRANÇOIS, P. (dir.). La musique: une industrie, des pratiques. Paris: La Documentation Française, 2008. p. 134-152.

ISNARD, H. O espaço do geógrafo. Boletim Geográfico. Rio de Janeiro, n. 258-259, p. 5-17, jan./dez. 1978.

KIRKWOOD, H. Rapping rebellion: hip hop as a new social movement in Cuba. Latin American Urban Politics, May 2, 2006. Disponível em: http://lanic.utexas.edu/project/ etext/llilas/ilassa/2007/kirkwood.pdf. Acesso em: 13 maio 2021.

OLAVARRIA, M. Rap and revolution: hip-hop comes to Cuba. NACLA Report on the Americas, v. 25, n. 6, p. 28-30, 2002. doi: https://doi.org/10.1080/10714839.2002. 11722523.

PALET, R. M. Particularidades del proceso de urbanización en Cuba. La Habana: Academia de Ciencias de Cuba, 2017.

PERRY, M. Negro soy yo: hip hop and raced citizenship in neoliberal Cuba. Durham, NC: Duke University Press, 2016.

RAMÍREZ, S. A. El rap y el "afrocubano pensamiento": entrevistando a Obsesión. Otras Modernidades, Milão, IT, n. 6-11, p. 277-280, 2011.

RIBEIRO, A. C. T. Dança dos sentidos: na busca de alguns gestos. In: BRITTO, F. D.; JACQUES, P. B. (org.). Corpocidade: debates, ações e articulações. Salvador: UFBA, 2010. p. 26-41.

RIBEIRO, A. C. T. Lugares dos saberes: diálogos abertos. In: BRANDÃO, M. A. Milton Santos e o Brasil: território, lugares e saber. São Paulo: Fundação Perseu Abramo, 2004. p. 17-27.

RIBEIRO, A. C. T. Pequena reflexão sobre categorias da teoria crítica do espaço: território usado, território praticado. In: SOUZA, M. A. (org.). Território brasileiro: usos e abusos. Campinas, SP: Territorial, 2003. p. 29-40.

RODRIGUEZ, Y. Lidando com mi passa. Movimiento - La Revista Cubana de Hip Hop, n. 9, p. 16-22, mayo/ago. 2010.

SELLER CRESPO, Y. Movimiento de rap cubano: nuevas identidades sociales a través de la cultura hip hop. In: PODER Y NUEVAS EXPERIÊNCIAS DEMOCRÁTICAS EN AMÉRICA LATINA Y EL CARIBE. Buenos Aires: Clacso, 2005. Disponível em: http://biblioteca.clacso.edu.ar/clacso/becas/20200131125046/selier.pdf. Acesso em: 13 maio 2021. 
SANTOS, M. A natureza do espaço. São Paulo: Hucitec, 1997.

SANTOS, M. Técnica, espaço e tempo. São Paulo: Hucitec, 1994.

SANTOS, M. A formação sócio-espacial como teoria e como método. Boletim Paulista de Geografia, n. 54, p. 81-100, 1977.

SANTOS, M.; SILVEIRA, M. L. O Brasil: território e sociedade no início do século XXI. Rio de Janeiro: Record, 2001.

SILVEIRA, M. L. Economia política e ordem espacial: circuitos da economia urbana. In: SILVA, C. Território e ação social: sentidos da apropriação urbana. Rio de Janeiro: Faperj/ Lamparina, 2011. p. 35-51.

SMITH, N. Desenvolvimento desigual: natureza, capital e a produção do espaço. Rio de Janeiro: Bertrand Brasil, 1988.

TOOP, D. Rap attack 3: African rap to global hip hop. London: Serpent's Tail, 2000.

ZURBANO, R. Raza y política en la Cuba del siglo XXI. La Habana: Casa de las Américas, 2012.

ZURBANO, R. Mami, no quiero más reguetón! Movimiento - La Revista Cubana de Hip Hop, n. 6, p. 4-12, 2009.

Recebido em: 19 abr. 2021 Aprovado em: 13 maio 2021 